CuPAUAM. 15-1988

\title{
ESTUDIO DE LA INDUSTRIA EN ASTA DE CIERVO DE EL SOTO DE MEDINILLA
}

\author{
CORINA LIESAU VON LETTOW-VORBECK
}

\section{Resumen}

A través del estudio de los útiles en asta procedentes del yacimiento vallisoletano de El Soto de Medinilla hemos querido abordar tanto aspectos metodológicos, terminológicos como las técnicas de extracción empleadas. Para una sistematización más clara se ha tenido también en cuenta el origen anatómico de las diferentes piezas, factor condicionante para la finalidad de cada útil, haciendo especial hincapié en el análisis de las piezas denominadas como mangos.

\section{Summary}

Through the study of the antler tools from site of El Soto de Medinilla (Valladolid) we have tried not only to come to the metodological, and terminological aspects but algo to the kind of extraction system used. It has also been taken into consideration the anatomical origin of the different units, a very important factor for the utility of each tool with special stress on the analisis of the tools known as "shafts".

\section{Introducción}

Hasta el momento actual, los estudios sobre industria ósea se han centrado en períodos, como el Paleolítico Superior y el Neolítico, mientras que la Edad de los Metales y, sobre todo, la etapa aquí tratada, presenta grandes lagunas, con lo que a menudo, toda la información obtenida de las excavaciones se reduce a un comentario escueto sobre el hallazgo de huesos decorados o algunas piezas utilizadas como mangos.

Como principio fundamental, creemos que se debe intentar unificar todos los criterios que nos permitan ver la evolución, tanto de la industria ósea como de la de asta, a lo largo de los distintos períodos pre y protohistóricos, empleando no sólo un lenguaje común y una técnica analítica uniformada, sino también una tipología, que haga posible estudiar todos los objetos elaborados en dichas materias, independientemente de su contexto cronológico. 
Nuestro principal objetivo es profundizar en el estudio de las astas trabajadas de ciervo (Cervus elaphus L.) a través del material procedente de las últimas excavaciones de urgencia realizadas en El Soto de Medinilla de las cuales ya ha sido facilitado un avance por Escudero (1988). No quedan incluidos en nuestro estudio útiles elaborados en hueso, documentados por dicha autora, ni una pieza de asta, actualmente analizada por los arqueólogos excavadores.

En los dos niveles de ocupación vaccea, se han podido diferenciar algunas estructuras de cabañas, pavimentos de cantos rodados, un posible conjunto-ofrenda y varios basureros de diferentes dimensiones presentando todos ellos abundantes restos faunísticos, cerámica, útiles fragmentados etc.

Las piezas trabajadas en asta, aunque no muy abundantes, nos han permitido emprender una línea de estudio, en la que se tenga también en cuenta el origen anatómico de los útiles para así, en posteriores evaluaciones estadísticas, llegar a conclusiones más definidas en cuanto a su funcionalidad y abundancia. Al ejercer la mayoría de ellos una función pasiva, se podrá en un futuro también, aunque de forma indirecta, determinar la representatividad de los vástagos enmangados, normalmente metálicos, perdidos, desintegrados o reciclados; y por lo tanto, escasos como hallazgos arqueológicos.

\section{Metodología}

Las piezas trabajadas en asta no ofrecen tantas dificultades de identificación, a diferencia de los útiles en hueso (especialmente en objetos pequeños), en los que la mayoría de las veces es imposible no sólo determinar la porción anatómica de la que procede un útil, sino también averiguar qué especie ha ofrecido la materia prima para su elaboración:

- El asta es una materia que por sus características particulares resulta bastante fácil de reconocer; sólo si la pieza es de reducido tamaño y está muy trabajada puede ser conflictiva su identificación específica (ciervo, corzo, para el período que aquí tratamos).

- Por otro lado, en la mayoría de los casos es también posible determinar el origen anatómico tanto de los útiles, como de los objetos semi-elaborados, e incluso, de los desechos de talla.

Con respecto a la sistematización de la industria ósea que hemos empleado para el estudio del material, tenemos varios trabajos útiles, como el de Ruiz Nieto et alii (1983), que sintetiza en castellano, entre otros, los criterios utilizados por Camps-Fabrer (1979) y Voruz (1978) en la descripción de los útiles, su orientación y representación (Camps-Fabrer y Stordeur, 1979), como la terminología acuñada por Billamboz (1979) para la denominación de las diferentes partes del asta de los cérvidos. A su vez la lista-tipo de Rodanés (1987) nos ofrece la posibilidad de clasificar algunas piezas aquí estudiadas, pero sería de sumo interés poder seguir ampliando su tipología para englobar en ella útiles frecuentes para el período celtibérico.

El material de los dos niveles se ha estudiado conjuntamente, ya que no hay diferencias cronológicas ni culturales acusadas entre ellos y las facturas, huellas de la extracción o elaboración y de uso se han examinado por el método visual directo, sin entrar de momento, en 
detalles macroscópicos. Como ya ha apuntado Rodanés (1987-38), es muy difícil distinguir las técnicas de extracción de las de la elaboración, más aún, cuando el útil está muy trabajado. Por lo tanto la ficha analítica de un objeto en hueso propuesta por Ruiz Nieto et al. (1983) no resulta del todo adecuado para el estudio de nuestro material.

$\mathrm{El}$ asta presenta una textura mucho más porosa, frágil y menos compacta que el hueso. Los factores extremos actúan con más intensidad sobre la superficie exterior e interior del objeto, por lo que diferenciar posibles huellas de uso y elaboración tampoco parece ser una tarea fácil, ni fiable. La posibilidad de diferenciar estas técnicas se debe en gran medida al tipo de útil analizado, el grado de transformación que requiere, las técnicas de trabajo y los útiles o material de los que se dispone en su elaboración.

Para la descripción de los objetos trabajados en asta hemos utilizado la siguiente ficha:

Unidad: Unidad arqueológica de la que procede el objeto.

Estado: Completo/incompleto, fracturas, si está quemado/calcinado, etc.

Orígen: Orígen anatómico de la pieza según las directrices propuestas en este trabajo.

Medidas: Longitud máxima (LM), anchura medial (A) y espesor medial (E), expresando estos valores entre paréntesis si el objeto está incompleto, fracturado, deformado, etc.

Tipo: Hemos estudiado el material con los criterios tipológicos de Rodanés (1987), excepto en aquellos útiles en los que no fue posible, como por ejemplo los mangos.

Descrip.: Descripción de la extremidad distal, el fuste, la extremidad proximal y las caras superior e inferior del objeto.

Observ: Algún dato o característica adicional que presente la pieza.

Las medidas de las piezas se han expresado en milímetros, redondeando en este caso los decimales, ya que sobre todo en la anchura y el espesor medial pueden variar algo en cada toma de medida. En las piezas clasificadas como mangos también hemos considerado interesante tomar medidas, como la longitud o el diámetro máximo, tanto interior como exterior. La longitud máxima se ha medido en las luchaderas con un hilo colocado en la cara interior del objeto y posteriormente dicha medida comparada con la regla milimetrada.

Durante el proceso de la excavación se han inventariado unas 64 piezas de asta y hueso, que a simple vista parecían estar trabajadas. Después de estudiar y seleccionar el material, hemos preferido dar una enumeración distinta a la del inventario que resulta más coherente para las piezas aquí tratadas (1).

\section{Algunas cuestiones terminológicas}

Antes de entrar en analizar el material que a continuación se expondrá, queremos brevemente a través de un esquema ilustrado especificar la terminología acuñada por Billamboz:

(1) Los números entre paréntesis van a indicar los antiguos números del inventario de la excavación: 1(26), 2(17), 3(62), 4(64), 5(25), 6(22), 7(60), 8(27), 9(34), 10(31), 12(5), 13(50), 14(56), 15(24), 16(4), 17(33), 18(55), 19(11), 20(3), 21(45), 22(29), 23(11), 24(8), 25(49), 26(54), 27(35), 28(53). 


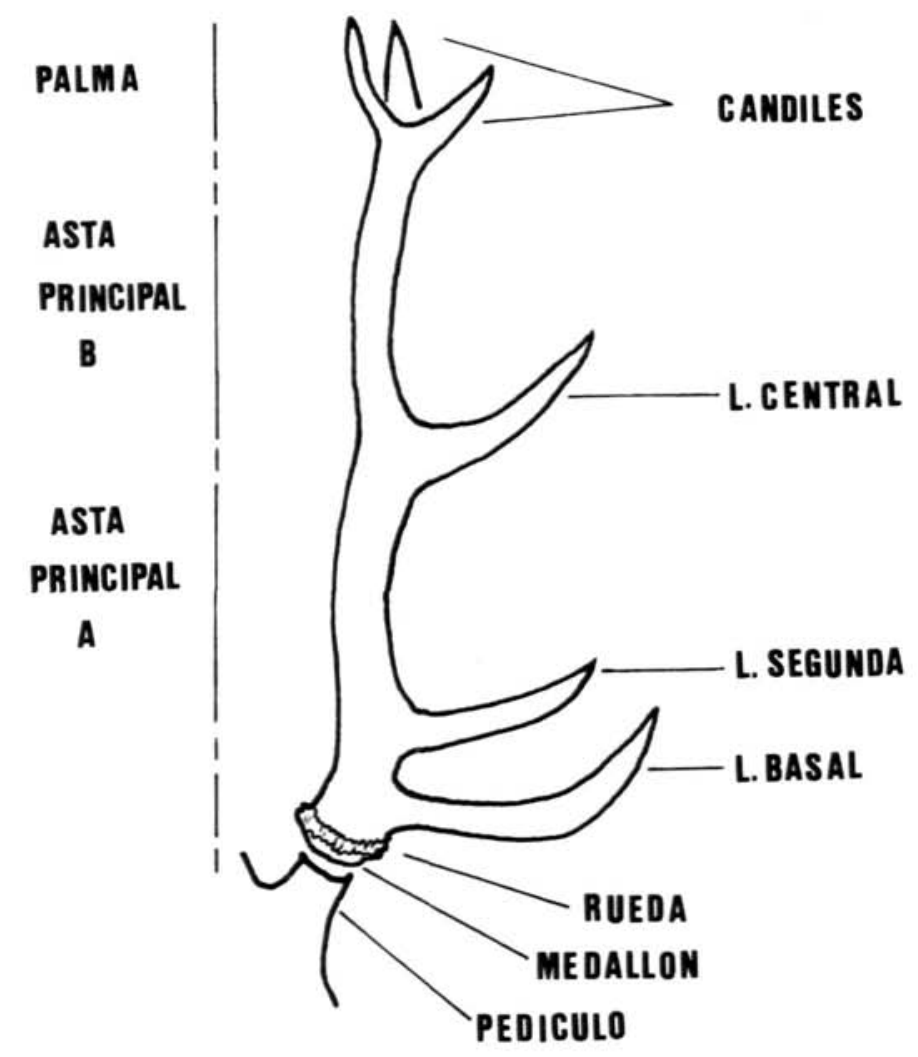

FIG. 1. - Terminología descriptiva de las diferentes partes del asta del ciervo, según Billamboz (1979, 96).

También queremos añadir, que para la descripción de los útiles, hay que mencionar que la superficie, sobre todo en la cara exterior del asta principal A y B, presenta numerosas rugosidades, que denominaremos perlado. A su vez, toda la cornamenta está recorrida por una serie de canales que denominaremos ranuras, siendo éstas los vestigios de los vasos sanguíneos que alimentaron la cornamenta durante su desarrollo.

Billamboz (1979) diferencia entre luchadera basal, luchadera segunda, luchadera central y candiles. Nosotros, a la hora de trabajar con el material elaborado, hemos obviado hacer estas diferenciaciones, por varios motivos:

- Aunque dicho autor ha podido reconocer varias características para cada pieza de la cornamenta, la variabilidad morfológica que presentan las astas de los cérvidos es muy grande (tanto inter como intraindividualmente), dependiendo de la edad del animal, condiciones de alimentación y de medioambiente. No sólo se desarrolla la cornamenta de un ciervo a medida que va alcanzando la madurez (Hoffmann 1959, 
12), sino que las propias luchaderas cambian su morfología. Así, por ejemplo, la luchadera basal en animales viejos cambia su curvatura, adquiriendo, en perfil, un quiebro muy característico, lo que naturalmente va a influir en su elección como útil.

- Por otra parte, como el mismo autor señala, la segunda luchadera no se desarrolla en todos los machos, lo que puede llevar a confusiones a la hora de la identificación de estas piezas. En El Soto de Medinilla algunos hallazgos de astas mudadas alcanzan un tamaño considerable, adquiriendo incluso los candiles respectivos, longitudes y grosores comparables a las luchaderas de unas cornamentas más pequeñas. Este hecho en productos de desbastado, o útiles que no necesitan de un proceso de elaboración más complicado puede hacer reconocible la procedencia de las diferentes luchaderas, pero cuando las piezas están muy talladas, es prácticamente imposible reconocer su sección original, como también las características que presentan el perlado o las ranuras, factores éstos muy importantes a la hora de identificar el origen anatómico de dichas piezas.

- Por último, su morfología no presenta grandes diferencias, por lo que uno de los criterios fundamentales para su elección como útil va a ser más bien su tamaño, grosor, curvatura y "calidad" (fundamentalmente el grado de calcificación).

De momento, hemos distinguido en nuestra sistematización los objetos procedentes del asta principal A o B, aunque seguramente esta diferenciación en cuanto al origen no influya demasiado en la elaboración de la mayoría de los útiles, por ser unas zonas con características muy parecidas.

\section{Estudio del material}

Para los pobladores de El Soto de Medinilla la industria realizada en asta debió tener cierta importancia, ya que no sólo separaban del neurocráneo y pedículo las cornamentas de los ciervos cazados, sino que también hemos podido evidenciar una recogida intencional de las astas mudadas (Liesau 1989, 133).

De un total de 128 fragmentos y objetos de asta hallados, sólo la mitad presenta vestigios de manipulación o trabajo humano. Hemos diferenciado dos grupos de piezas:

- Aquellos hallazgos que presentan cortes, fracturas por flexión o torsión, útiles fragmentados, piezas poco elaboradas, amortizadas o incluso "malogradas", difíciles de clasificar tanto por su forma como por su posible funcionalidad.

- Piezas que por su morfología y acabado se pueden denominar como útiles. Se consideran como tales las piezas n. ${ }^{\circ} 1,3,4,6,9,14,15,16,17,18,19,20,21,22,25,26$ y 27.

No hemos querido prescindir totalmente del primer grupo, ya que no siempre resulta fácil diferenciar las piezas que a nuestro modo de ver resultan poco elaboradas, de aquellas otras, que por su funcionalidad necesitan de un proceso de elaboración más complicado. Por otra parte, se perdería una información que, a la larga, puede ser valiosa, en cuanto que estos objetos semi-elaborados pueden revelarnos técnicas de extracción o de trabajo, que en lo útiles elaborados ya no son posibles de averiguar. 
FIG. 2. - Origen anatómico de las piezas trabajadas en asta de ciervo.
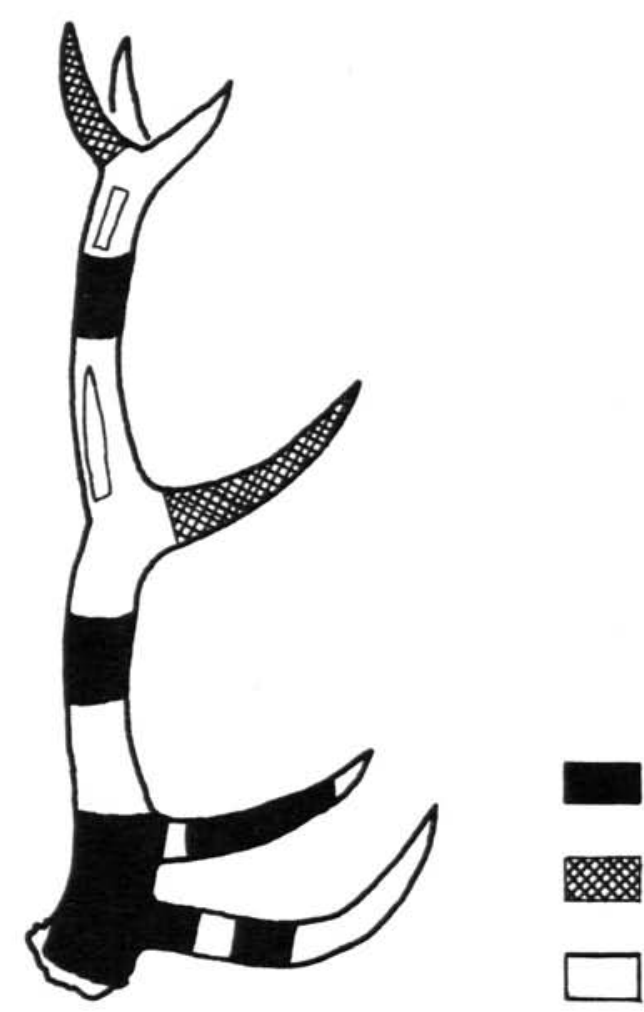

M AMGOS APUNTADOS

VARILLAS

V. Origen de las piezas

A la hora de elaborar los útiles en asta, se aprovechan al máximo todas las características que presentan las diferentes partes de la cornamenta, tales como la forma apuntada de las luchaderas o la zona más dura en el arranque del asta. De este modo, y aunque no sean muchas las piezas a las que podamos atribuir una morfología y una función clara, ha sido posible observar un cierto patrón de comportamiento en cuanto a su origen:

- Todas las piezas apuntadas, como los punzones, las cuñas, el útil n. ${ }^{\circ} 6$, algún biselado, aprovechando su morfología natural, se elaboran a partir de las luchaderas, (Fig. IV-VI).

- Las zonas del asta principal A y B se prestan a servir como fuente de materia prima para la obtención de diversas piezas a través de la técnicas de extracción de las varillas. De este modo, se obtienen unas láminas de asta más planas y de mayor grosor que las que se puedan conseguir a partir de las luchaderas. Sirvan de ejemplo las piezas representadas en la Fig. VII.

Los mangos proceden de diversos orígenes:

- Por un lado, tenemos aquellos mangos elaborados a partir del arranque del asta, rebajando en su totalidad la rueda y parte del medallón. (Figs. VIII, IX, 17 y X). 
- Una variante del primer tipo incluye, en su elaboración, parte de la primera luchadera (Fig. XI).

- Como mangos se han utilizado también piezas procedentes del asta principal tanto A como B, cuestión esta última en la mayoría de los casos difícil de apreciar, ya que prácticamente todas las piezas presentan el fuste descortezado, con lo cual su sección y superficie original, como elementos distintivos se han visto muy alterados. Pueden presentar un vaciado total, retirando la estructura interior esponjosa medular, como por ejemplo en la Fig. XII, n. ${ }^{\circ} 21$ y 23 o parcial, como el n. ${ }^{\circ} 16$ (Fig. IX).

- Por último se han utilizado también las luchaderas como fuente de materia prima para fabricar a partir de ellas, mangos de menor tamaño.

\section{Técnicas de extracción y elaboración}

Se conocen ya algunos estudios de arqueología experimental sobre industria ósea elaborada principalmente con útiles líticos (Dauwois, 1977, Semenov, 1981, Murray, 1979, Stordeur, 1979, Newcomer, 1974 etc.), pero destaca la ausencia de trabajos en los que se hayan empleado instrumentos metálicos para su elaboración. Tanto en el estudio del troceado y descuartizamiento de los restos faunísticos observados, como en el trabajo de las astas se han podido evidenciar la utilización de diferentes útiles metálicos como podrían ser cuchillos, hachas y sierras.

Somos conscientes de que las piezas aquí documentadas se han analizado sólo de forma visual directa y en espera de que futuros trabajos experimentales puedan confirmar, no sin ciertas reservas, las siguientes afirmaciones:

En el proceso de extracción podemos apreciar una eliminación de las luchaderas del asta principal, tanto por flexión, cortes horizontales y oblícuos, o incluso el aserrado (como también la combinación de todos ellos entre sí).

Las sierras metálicas, ya conocidas en la Península Ibérica desde el III Milenio, y documentadas como tales en Millares (Leisner, 1943, lám. 20. 2,4 y lám. 20. 3,2) y Cueva II de Marroquíes Altos (Berdichewesky, 1964, Fig. 57, 5 y 6), también se han hallado en Numancia. donde se ha evidenciado una hoja de sierra forjada en hierro (Manrique, 1980, 154) o en La Caridad (Vicente Redón et alii, 1986, 11), por lo que pensamos que no sería improbable que fueran utilizadas en nuestro yacimiento, aunque no se hayan atestiguado arqueológicamente.

A nuestro entender, tendríamos como buenos ejemplos de aserrado horizontal, los útiles n. ${ }^{\circ} 1$ (Fig. IV), n. ${ }^{\circ} 6$ (Fig. VI) y n..$^{\circ} 25$ (Fig. XIII), que presentan una superficie muy plana en su extremo proximal/distal en la que ha quedado reflejada las características rayas paralelas del aserrado e incluso el cambio direccional en tangente del filo, al ir cortando ambas superficies.

Otra técnica de extracción, sobre todo aplicada en la zona del asta principal A o B, sería la técnica de extracción de las varillas, ya constatada por Rust $(1937,1943)$ en dos yacimientos alemanes del Paleolítico Superior. Se realizan dos surcos longitudinales que recorren la 
superficie exterior dura del asta y se introduce posteriormente algún objeto por debajo de esta zona para separar la varilla del tejido medular interior. Tanto el colgante n. ${ }^{\circ} 9$ (Fig. VII), como las piezas poco elaboradas $\mathrm{n} .^{\circ} 10$ y 11 (cuyas medidas son muy similares en su extremo apuntado) y también los n. ${ }^{\circ} 12$ y 13 (seguramente piezas de desecho) deben haber sido extraídos por esta técnica.

Ya en cuanto el proceso de elaboración de los útiles nos resulta mucho más difícil diferenciar a simple vista entre huellas de elaboración, huellas de uso, o aquellas producidas por factores de erosión, sedimentación, etc. Lo que sí cabe anotar, es el descortezado de algunas piezas como los mangos, o incluso el facetado (Fig. XII, 24), rehundido (¿con cuchillos?), perforado e incluso pulido (Fig. XIII, 27) de algunos útiles.

\section{Sistematización propuesta}

Antes de entrar más a fondo en el análisis de los mangos, que representan casi las $2 / 3$ partes del conjunto de los útiles, queremos brevemente comentar las demás piezas halladas.

Dentro del grupo denominado por Rodanés (1987) de los APUNTADOS hay que destacar que el punzón en hueso o asta, muy frecuente en períodos anteriores al celtibérico, sólo se ha documentado claramente con la pieza n. ${ }^{\circ} 1$ (Fig. IV), mientras que las piezas n. 3 (que al estar fragmentado su extremo distal, también podría ser un biselado) y 5 (Fig. V) que no acusan un facetado tan apuntado.

Nos merece una atención especial el útil n. 6 (Fig. VI), de los que varios ejemplares han sido hallados en La Hoya y que según Llanos (1983, 121), se pueden considerar como silbos. Esta pieza, a diferencia de estos últimos, presenta su extremo distal apuntado a modo de facetas. A su vez, no todos los ejemplares de La Hoya presentan su fuste rebajado, sino una simple perforación. No queremos entrar en deliberar si con ello cambia su funcionalidad y sólo un estudio exhaustivo de muchas piezas podrá aclarar estas diferencias morfológicas.

En la muestra tenemos también algún BISELADO (Fig. V, 4 y Fig. VI, 7), dentro de los PERFORADOS, un colgante (Fig. VII, 9) y los restantes útiles entrarían en el apartado de los DIVERSOS, en los que Rodanés $(1987,176-178)$ incluye aquellos objetos que no sobrepasen un $10 \%$ en abundancia respecto al total de las piezas de una muestra, siendo los mangos en los períodos por él estudiados (Neolítico-Edad del Bronce) muy escasos. Es evidente, que para el período celtibérico los mangos se deben catalogar como un grupo aparte.

Aunque en la muestra los mangos sean los útiles más abundantes, los resultados obtenidos a partir del estudio de sólo 14 piezas, sirven para intentar ver, a modo de ensayo, las características que presentan.

Vamos a diferenciar entre:

1. Mangos de forma cilíndrica con el extremo proximal cerrado.

En estas piezas se aprovecha la zona de máxima calcificación en el arranque del asta, rebajando la rueda y el nacimiento de la primera luchadera, para obtener así una superficie plana o ligeramente redondeada. A su vez se aprovecha la zona más calcifi- 
cada, y por lo tanto más dura en el interior, sobre la que ejercerá toda la presión el vástago. En este grupo se incluyen los mangos 14, 15 (Fig. VIII), 17 (Fig. IX), y 18 (Fig. X).

2. Mangos de forma cilíndrica que en su extremo proximal incluyen parte de la primera luchadera.

También en este tipo se ha rebajado la rueda pero, a diferencia del grupo anterior, parte de la luchadera basal permanece junto al arranque del asta (seguramente por razones de comodidad, ¿o acaso se debe a una funcionalidad diferente?). Como buenos ejemplos tenemos el n. ${ }^{\circ} 19 \mathrm{y} \mathrm{el} \mathrm{n.} 20$ (Fig. XI).

3. Mangos de forma cilíndrica con el extremo proximal abierto o cerrado.

Proceden del asta principal A o B y presentan una perforación total en su interior, como serían las piezas 21, 22 y 23 (Fig. XII), excepto la pieza n. ${ }^{\circ} 16$ (Fig. IX), cuyo extremo proximal no se ha vaciado completamente.

4. Mangos de unas dimensiones más reducidas, tanto de anchura como de espesor, con características diferentes a los grupos anteriores que se tratarán a continuación con más detalle. Con este grupo identificamos a los n. ${ }^{\circ} 25,26$ y 27 (Fig. XIII).

Aunque la muestra es muy pequeña, es posible observar ciertas diferencias entre los tres primeros tipos de mangos y el último. Hemos medido tanto el diámetro interior (o longitud máxima, si la huella dejada por el v́astago era de forma rectangular o cuadrada), como el exterior, viendo que ambos están muy relacionados entre sí, cuestión muy lógica, ya que las dimensiones del mango están en función del vástago que se pretende introducir en él.

En los tres útiles del grupo 4, el diámetro interior no sobrepasa el valor de $10 \mathrm{~mm}$., mientras que el diámetro exterior no sobrepasa los $30 \mathrm{~mm}$. En cambio, en todos los restantes mangos el diámetro interior nunca llega a tener un valor menor de $10 \mathrm{~mm}$. y el diámetro exterior sobrepasa siempre los $30 \mathrm{~mm}$., siendo la media de ambos unos $20 \mathrm{~mm}$. y $40 \mathrm{~mm}$. respectivamente.

Proponemos, por lo tanto, desarrollar una sistematización que sea funcional y a la vez nos informe sobre el origen anatómico de la pieza. El esquema que aquí se presenta cubre las necesidades del material estudiado, y presenta la ventaja de poder ser ampliado, a medida que aparezcan otros útiles.

Por una parte, la letra va a indicar la procedencia anatómica de la pieza: Considerando los candiles y las luchaderas como una unidad, asignamos a la pieza las letras "D", "E" y «F», según la porción elegida para elaborar el útil; es decir, en la letra «D» y "E» incluimos toda la luchadera desde su arranque, pero en la letra «E» se ha eliminado la extremidad distal, mientras en la «F» sólo se utiliza la porción medial de la luchadera.

La numeración nos revelará el tipo, pudiendo aplicarse el sistema según la lista-tipo de Rodanés (1978), aunque para algunos tipos habría que crear nuevos apartados y readaptar la numeración existente, o también provisionalmente del siguiente modo (dando por ejemplo el n. 1 al útil más frecuente dentro de la muestra, que para este período son sin duda alguna los mangos: 


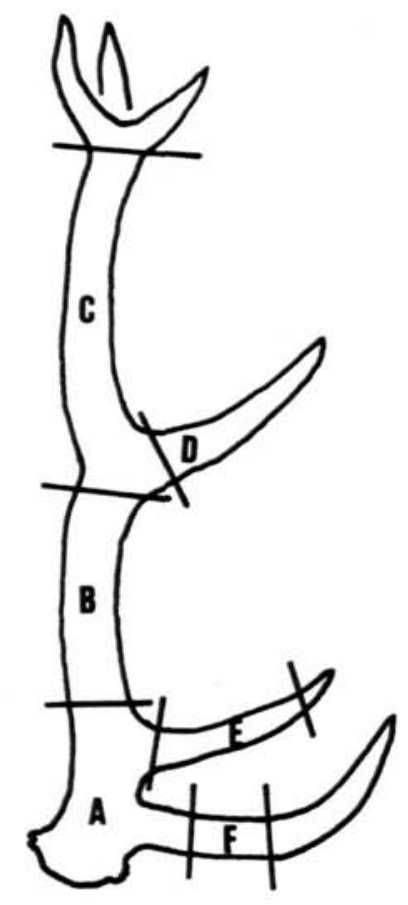

FIG. 3. - Sistematización propuesta para los útiles en asta.

1.A. Mango procedente del arranque del asta.

1.1.A. Mango con parte de la luchadera basal.

1.B. Mango procedente del asta principal A.

1.B/C. Mango procedente del asta principal A o B.

1.C. Mango procedente del asta principal B.

1.E. Mango procedente de luchadera.

1.F. Mango procedente de la parte medial de una luchadera.

2.D. Punzón procedente de una luchadera completa.

3.B/C. Colgante procedente del asta principal A o B.

4.D. Piezas como la $n .{ }^{\circ} 6$ (Fig. VI).

Los mangos también abundan en otros yacimientos celtibéricos. Aparte de las piezas halladas en las excavaciones antiguas en El Soto de Medinilla por Wattenberg (1959, lámina XII) que denomina como mangos de hoces, se han encontrado piezas muy similares en Roa de Duero, donde Sacristán (1986, lámina LXXII) distingue entre mangos grandes y pequeños (estos últimos servirían para cuchillos, punzones, etc.). Dicho autor menciona incluso mangos realizados a partir de cuernos de ovicaprinos, hecho que no se ha podido confirmar para nuestro yacimiento, pero que también han sido hallados por Abásolo et alii (1983) en Castrojeríz. A su vez Llanos $(1976,11)$ ha encontrado una amplia muestra de diferentes mangos en el yacimiento de la Hoya (Alava), que incluso han conservado los vástagos originales. 
Agradecimientos: En primer lugar nos gustaría expresar nuestra gratitud a Dr. Delibes y a Z. Escudero por permitirnos estudiar la industria en asta de esta últimas excavaciones, como también a la Dra. Blasco y al Dr. Fuentes por el apoyo y lectura crítica de este trabajo.

\section{Inventario}

Núm. 1 (Fig. IV)

Unidad: Basurero 2.

Estado: Completo, pero fracturado y algo deformado en la zona medial.

Origen: D.

Medidas: $\mathrm{L}=192, \mathrm{~A}=(25), \mathrm{E}=(22)$.

Tipo: Rodanés: 1.2.1. Punzón de base recta y sección oval-circular.

Por criterios exclusivamente tipométricos, al exceder los $180 \mathrm{~mm}$. de longitud, el autor ha creado un subtipo II, el de las puntas largas, aunque nosotros pensamos que se trata más bien de un punzón.

Descripción: Extremo distal tallado a modo de facetas, con una punta de sección ovalada. El fuste presenta una superficie pulida en la zona distal, mientras que el resto de la pieza conserva el perlado natural. El extremo proximal aserrado (metálico) horizontalmente, presenta en su borde izquierdo un corte limpio pero con un pequeña franja de materia que recorre verticalmente la superficie del corte. Seguramente es debido a que el cuchillo utilizado estuvo algo mellado en esta zona, no rebajando allí toda la materia al igual que en el resto de la superficie.

Observación: Util bien conservado, debido también a la buena calidad de la cornamenta en cuanto a su peso y, por lo tanto, su grado de calcificación. Tanto en el extremo proximal como distal las superficies presentan unas finas estrías paralelas, como huellas del proceso de elaboración.

Núm. 2 (Fig. IV)

Unidad: Basurero 2.

Estado: Completo, fracturado longitudinalmente.

Origen: D.

Medidas: $\mathrm{L}=146, \mathrm{~A}=(18), \mathrm{E}=(16)$.

Tipo: Poco elaborado, Rodanés: apuntados.

Descripción: Extremidad distal no trabajada, siendo la punta roma. El fuste está algo rebajado en la cara superior e inferior, confiriéndole a la sección una forma rectangular. La superficie no presenta perlado (¿pulida o erosionada?) y el extremo proximal está cortado horizontalmente, pero de manera más irregular que el $\mathrm{n} .^{\circ} 1$. 

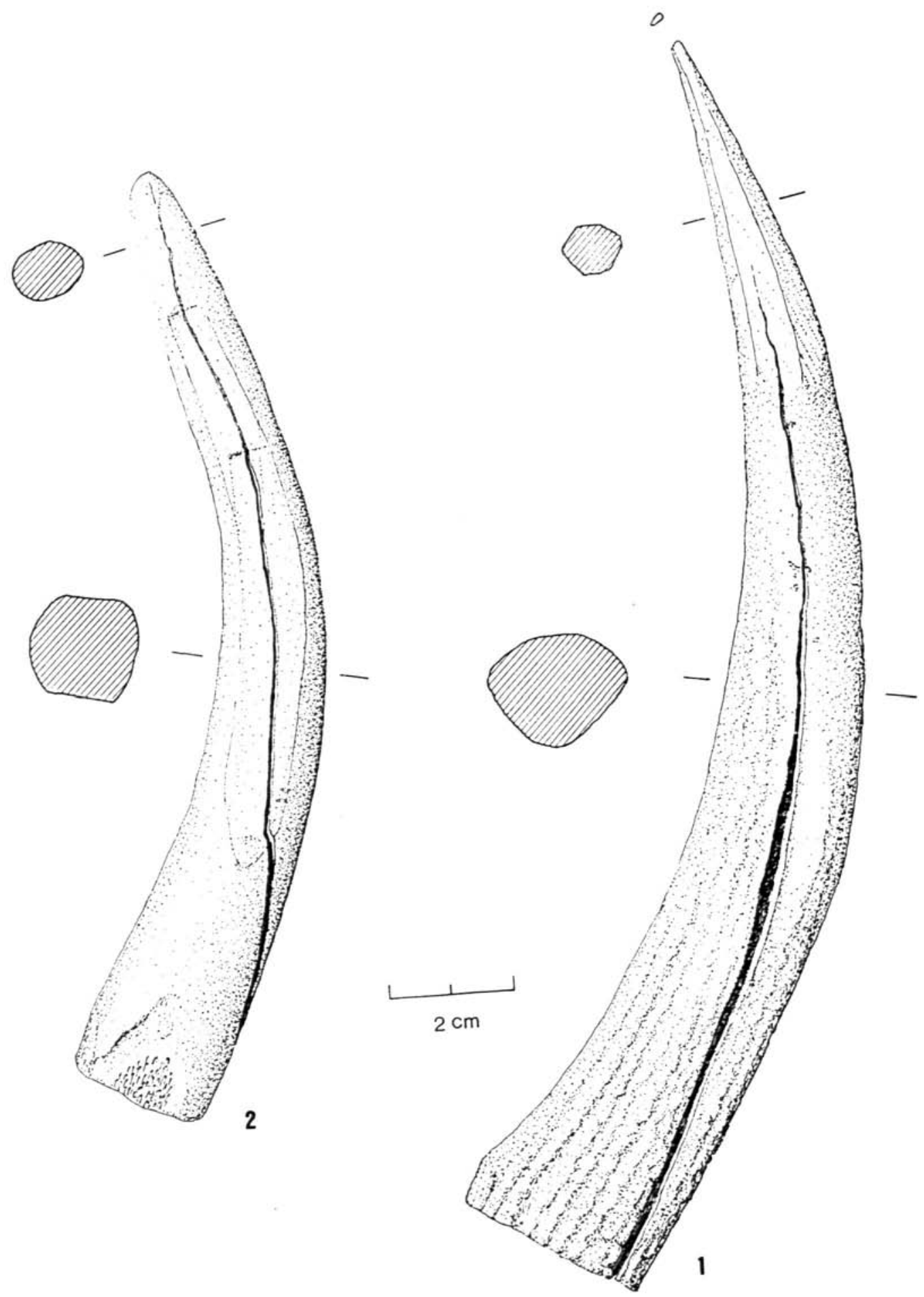
Núm. 3 (Fig. V)

Unidad: Habitación/Calle.

Estado: Incompleto, a falta del extremo distal, superficie en general mal conservada, con múltiples fracturas más o menos profundas, frágil.

Origen: D.

Medidas: $\mathrm{L}=(164), \mathrm{A}=(24), \mathrm{E}=(24)$.

Tipo: Rodanés: 1.2.3. Si realmente es un punzón (su longitud máxima excede con toda seguridad los $180 \mathrm{~mm}$., por lo que se consideraría también una punta larga) o un biselado.

Descripción: Extremidad proximal rebajada en la cara superior e inferior, con sección más bien rectangular, el fuste con sección circular no parece estar trabajado y el extremo proximal presenta un aserrado horizontal pero con el borde rebajado, mediante cortes oblicuos.

Núm. 4 (Fig. V)

Unidad: Material General.

Estado: Incompleto, en general bien conservado.

Origen: D.

Medidas: $\mathrm{L}=(87), \mathrm{A}=11, \mathrm{E}=9$.

Tipo: Rodanés: 24.2 cuña sin base.

Descripción: Extremidad distal y el fuste presentan la cara inferior totalmente plana. El extremo distal presenta una superficie algo "gastada" por el uso. El fuste está tallado tanto por la cara inferior, como por sus bordes. La pieza está fragmentada en su extremo proximal.

Núm. 5 (Fig. V)

Unidad: Basurero 2.

Estado: Incompleto, fractura en el extremo distal y fractura longitudinal en el fuste.

Origen: D.

Medidas: $\mathrm{L}=(73), \mathrm{A}=(19), \mathrm{E}=(11)$.

Tipo: Pieza poco elaborada, Rodanés: apuntados, o tal vez útil a falta de la parte activa.

Descripción: Parte del fuste y extremo distal totalmente tallado a modo de facetas, apareciendo en la punta el tejido medular interior. No presenta allí huellas de uso. 


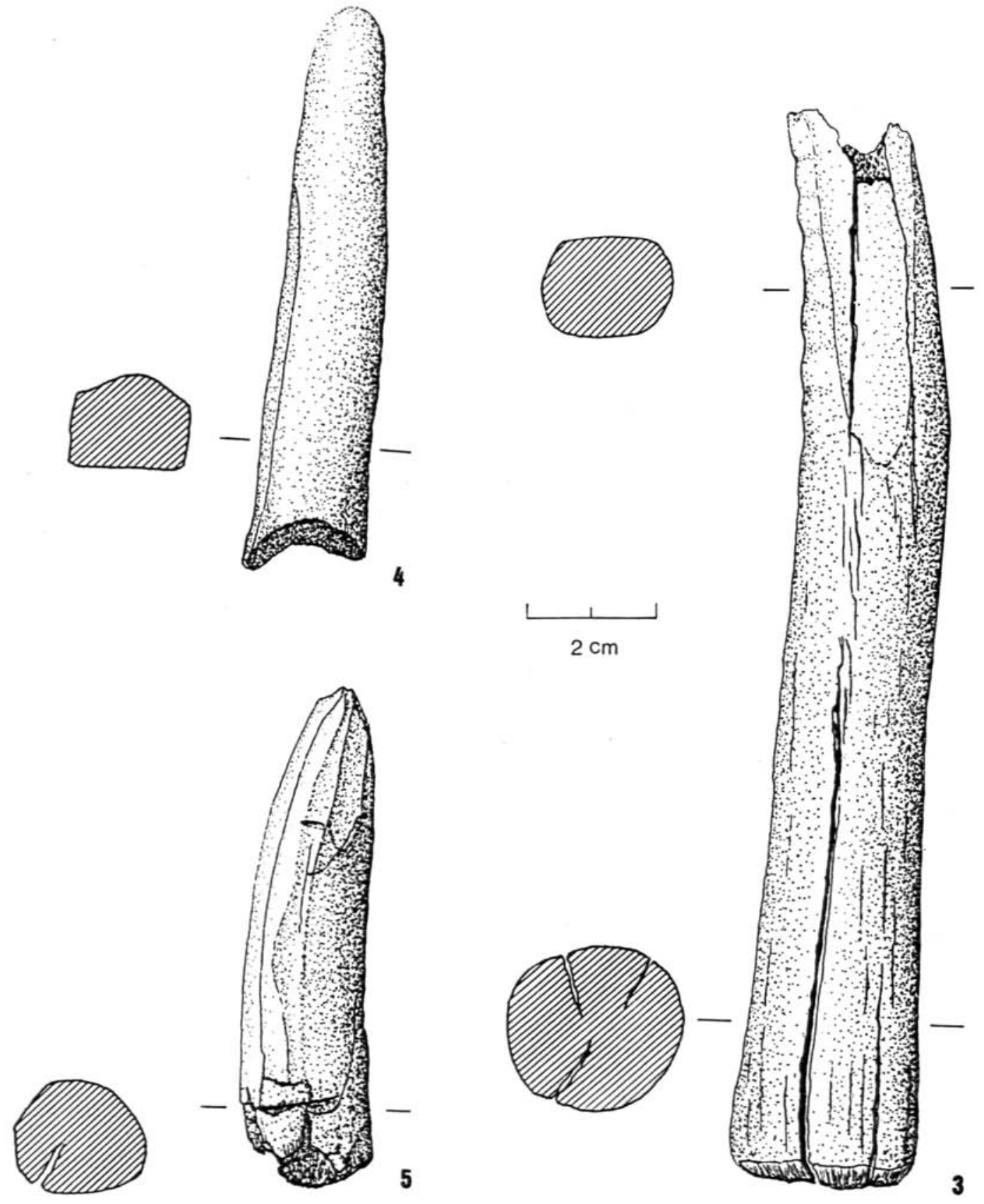


Núm. 6 (Fig. VI)

Unidad: Basurero 2.

Estado: Incompleto, pero muy bien conservado.

Origen: D.

Medidas: $\mathrm{L}=(117), \mathrm{A}=18, \mathrm{E}=19$ (en la zona no rebajada).

Tipo: Dentro de los apuntados habría que crear un nuevo subtipo.

Descripción: Extremo distal fracturado, pero apuntado a modo de facetas talladas. El fuste conserva en su parte proximal la morfología natural del asta, mientras que en su cara superior presenta un rebajado con parte del tejido medular vaciado realizado desde el extremo proximal. Este último está aserrado horizontalmente, presentando una perforación circular central, con un $\varnothing$ de unos $4 \mathrm{~mm}$. La superficie presenta numerosas estrías paralelas en dirección tangencial a la superficie cortada.

Observación: La pieza es de la misma "calidad" que el punzón $n .^{\circ} 1$, y su superficie se presenta (incluso el perlado) brillante (por uso o por elaboración).

Núm. 7 (Fig. VI)

Unidad: Habitación/Calle.

Estado: Completo.

Origen: D.

Medidas: $\mathrm{L}=51, \mathrm{~A}=12, \mathrm{E}=8$.

Tipo: Pieza poco elaborada, Rodanés: XI bisel lateral.

Descripción: El extremo distal presenta un biselado bilateral y no parece presentar huellas de uso. Toda la cara inferior es plana, siendo parte de una luchadera, cortada verticalmente por la mitad lo que le da una sección plano-convexa. La cara superior se presenta algo rugosa, con alguna ranura que recorre la pieza. El extremo proximal aparece cortado horizontalmente hasta llegar al tejido medular, donde posteriormente se ha flexionado, por lo que sobresale algo de dicha materia del plano cortado.

Núm. 8 (Fig. VI)

Unidad: Basurero 2.

Estado: Incompleto.

Origen: D.

Medidas: $\mathrm{L}=(67), \mathrm{A}=14, \mathrm{E}=10$. 

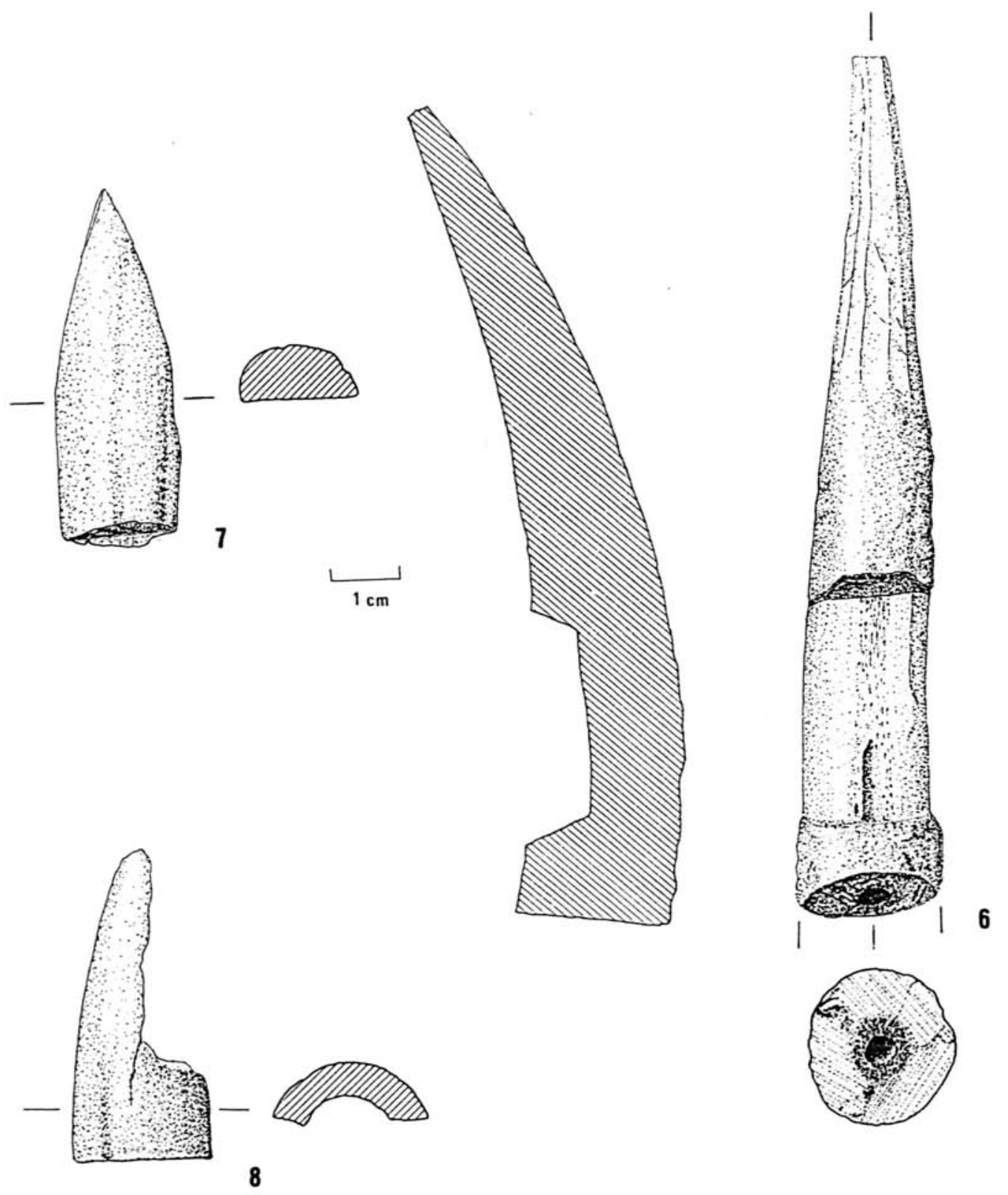
Tipo: No parece una pieza poco elaborada, pero por su estac fragmentado resulta difícil clasificarla.

Descripción: La extremidad distal está fracturada, incluso también el fuste en sentido vertical, (aunque ésto no podemos asegurarlo), con lo que la pieza tiene una sección cóncavoconvexa. En el borde derecho se ha realizado una perforación. Parte de la superficie está pulida (seguramente por el uso).

Núm. 9 (Fig. VII)

Unidad: Material General.

Estado: Completo.

Origen: $\mathrm{B} / \mathrm{C}$.

Medidas: $\mathrm{L}=67, \mathrm{~A}=14, \mathrm{E}=10$.

Tipo: Rodanés: 53.1. Colgante triangular.

Descripción: Extremo proximal cortado en dos planos oblicuos a la superficie de la pieza. Se clasifica como colgante al presentar una perforación realizada desde ambas caras. La cara inferior presenta restos del tejido medular, y la superior algo de perlado. El extremo proximal tiene forma apuntada por haberse recortado ambos bordes. La punta no parece presentar huellas de uso.

Núm. 10 (Fig. VII)

Unidad: Basurero 2.

Estado: Completo.

Origen: $\mathrm{B} / \mathrm{C}$.

Medidas: $L=127, A=17, E=9$.

Tipo: Pieza poco elaborada, Rodanés: XI, bisel lateral.

Descripción: En la extremidad distal la punta no parece tener huellas de uso, el fuste es plano en su cara inferior, mientras que en la superior conserva la morfología natural del asta principal. Ambos bordes están inclinados hacia la cara interior, la cual tiene así una anchura menor que la cara superior. El extremo proximal está cortado horizontalmente.

Núm. 11 (Fig. VII)

Unidad: Material General.

Estado: Incompleto.

Origen: B/C. 

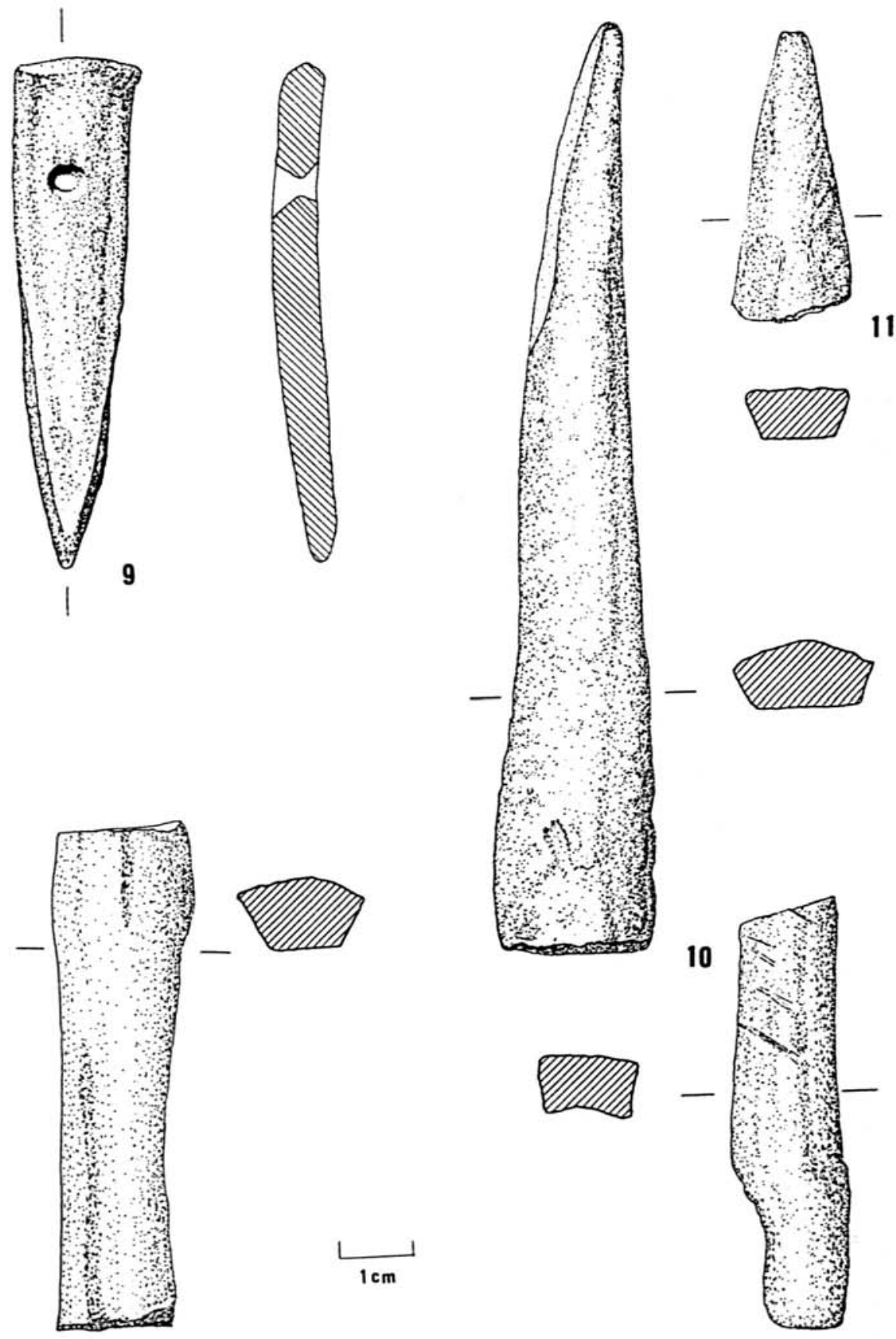

13

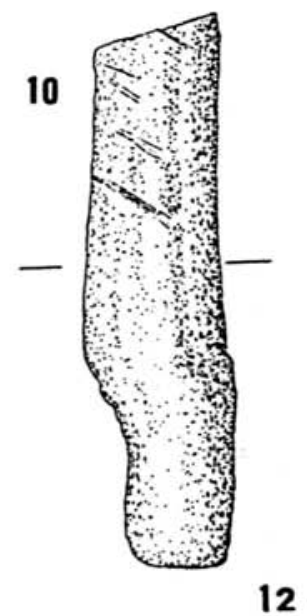


Medidas: $\mathrm{L}=(41), \mathrm{A}=13, \mathrm{E}=11$.

Tipo: Pieza poco elaborada, Rodanés: XI, bisel lateral.

Descripción: La extremidad distal está fragmentada en la punta, tanto la cara inferior como los bordes están recortados de forma similar que la pieza anterior. La extremidad proximal está incompleta.

Núm. 12 (Fig. VII)

Unidad: Material General.

Estado: ?

Origen: $\mathrm{B} / \mathrm{C}$.

Medidas: $\mathrm{L}=59, \mathrm{~A}=9, \mathrm{E}=9$.

Tipo: Pieza poco elaborada, posible desecho de talla.

Descripción: Tanto el extremo distal como el proximal parecen haber sido cortados horizontalmente y los bordes están cortados hasta la zona medial de la pieza, a partir de allí éstos por estar fracturados presentan un recorrido sinuoso. La cara inferior ha sido vaciada de forma irregular, mientras que la cara superior presenta varios cortes poco profundos en su superficie.

Núm. 13 (Fig. VII)

Unidad: Basurero 4.

Estado: Completo.

Origen: $\mathrm{B} / \mathrm{C}$.

Medidas: $\mathrm{L}=68, \mathrm{~A}=11, \mathrm{E}=10$.

Tipo: Pieza poco elaborada, posible desecho de talla.

Descripción: Presenta las extremidades, la cara inferior y los bordes cortados.

Núm. 14 (Fig. VIII)

Unidad: Conjunto Ofrenda.

Estado: Incompleto.

Origen: A.

Medidas: $\mathrm{L}=(77), \mathrm{A}=45, \mathrm{E}=38, \varnothing$ ext. $=(45), \varnothing$ int. $=$ ?

Tipo: A.1. 

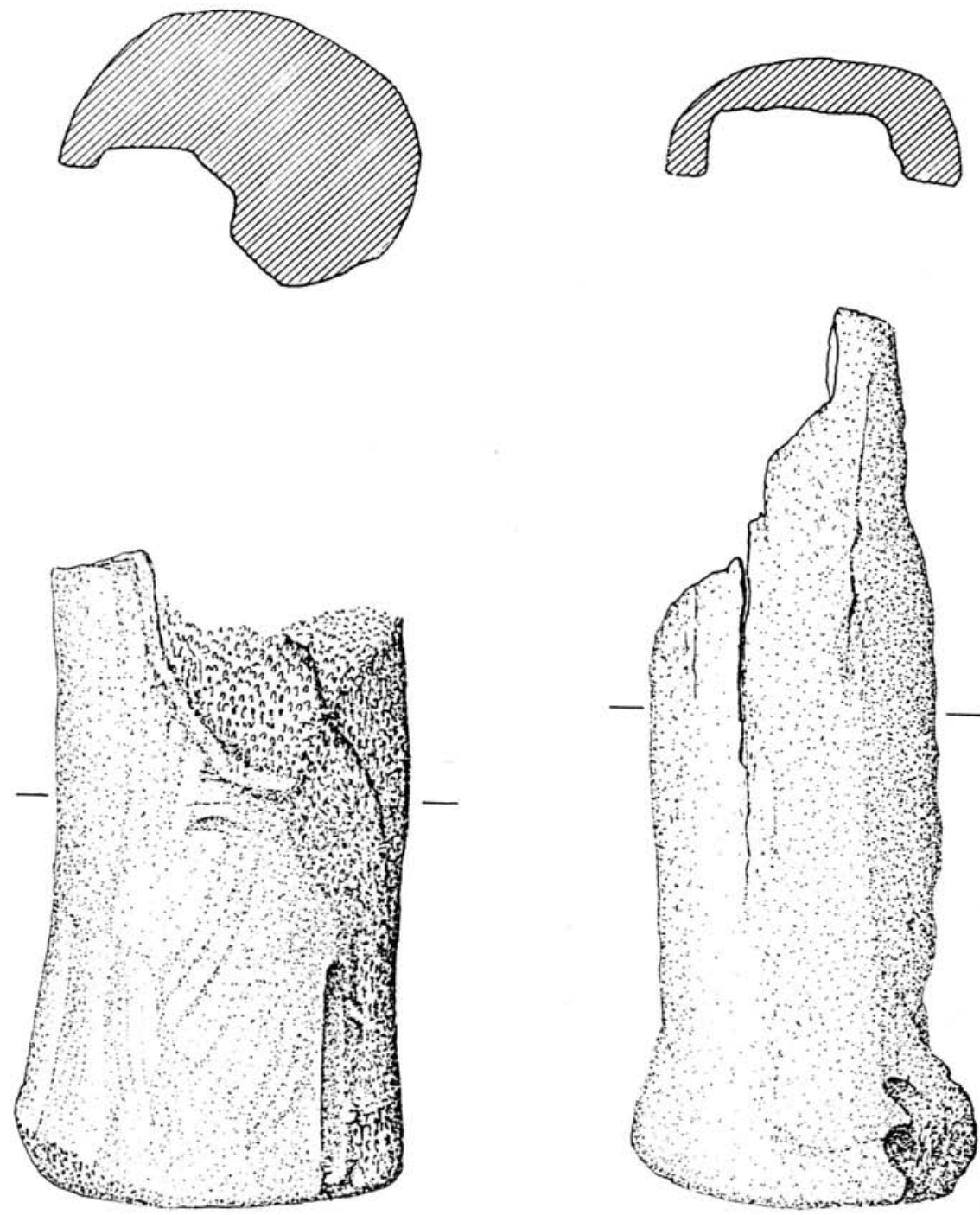

14

15

$2 \mathrm{~cm}$ 
Descripción: La extremidad proximal está fragmentada, por lo que no sabemos su longitud máxima. El descortezado en el borde derecho del fuste se ha realizado con tanta intensidad que ha desaparecido el tejido más calcificado exterior. En el fuste la superficie presenta zonas talladas y en la extremidad proximal se ha rebajado para obtener una superficie lisa con los bordes poco marcados. No se puede apreciar con claridad el vaciado interior, tanto por no estar vaciada hasta el fondo la pieza, como por la fragmentación que presenta el mango. Tampoco descartamos la posibilidad, de que alguna de estas piezas pudiese tener una función de machacador de materias blandas.

Núm. 15 (Fig. VII)

Unidad: Basurero 2.

Estado: Incompleto.

Origen: A.

Medidas: $\mathrm{L}=112, \mathrm{~A}=36, \mathrm{E}=$ ?, $\varnothing$ est. $=(36), \varnothing$ int. $=(24)$.

Tipo: A.1.

Descripción: Parece haberse conservado una pequeña parte del extremo distal, por lo que ha sido posible medir su altura máxima, pero la pieza está partida longitudinalmente por la mitad, presentando un tejido medular muy alterado. El extremo proximal ha sido rebajado de la misma forma que los otros mangos tipo A.1.

Núm. 16 (Fig. IX)

Unidad: Material General.

Estado: Completo (?), fractura longitudinal.

Origen: $\mathrm{B} / \mathrm{C}$.

Medidas: $\mathrm{L}=82, \mathrm{~A}=(31), \mathrm{E}=(36), \varnothing=35, \varnothing$ int. $=12$.

Tipo: B/C.1.

Descripción: El extremo distal presenta los bordes de la carta inferior fragmentados, mientras que en la cara superior aparecen tallados con dos grandes facetas. El fuste presenta un buen perlado y la extremidad proximal ha sido extraída por medio de varios cortes oblicuos profundos. Presenta un vaciado circular interior, que no sobrepasa los $10 \mathrm{~mm}$. de profundidad.

Observación: Posible pieza reutilizada, dejando la cara inferior sin trabajar, para que sirva, al mismo tiempo, de apoyo al vástago enmangado.

Núm. 17 (Fig. IX)

Unidad: Material General. 

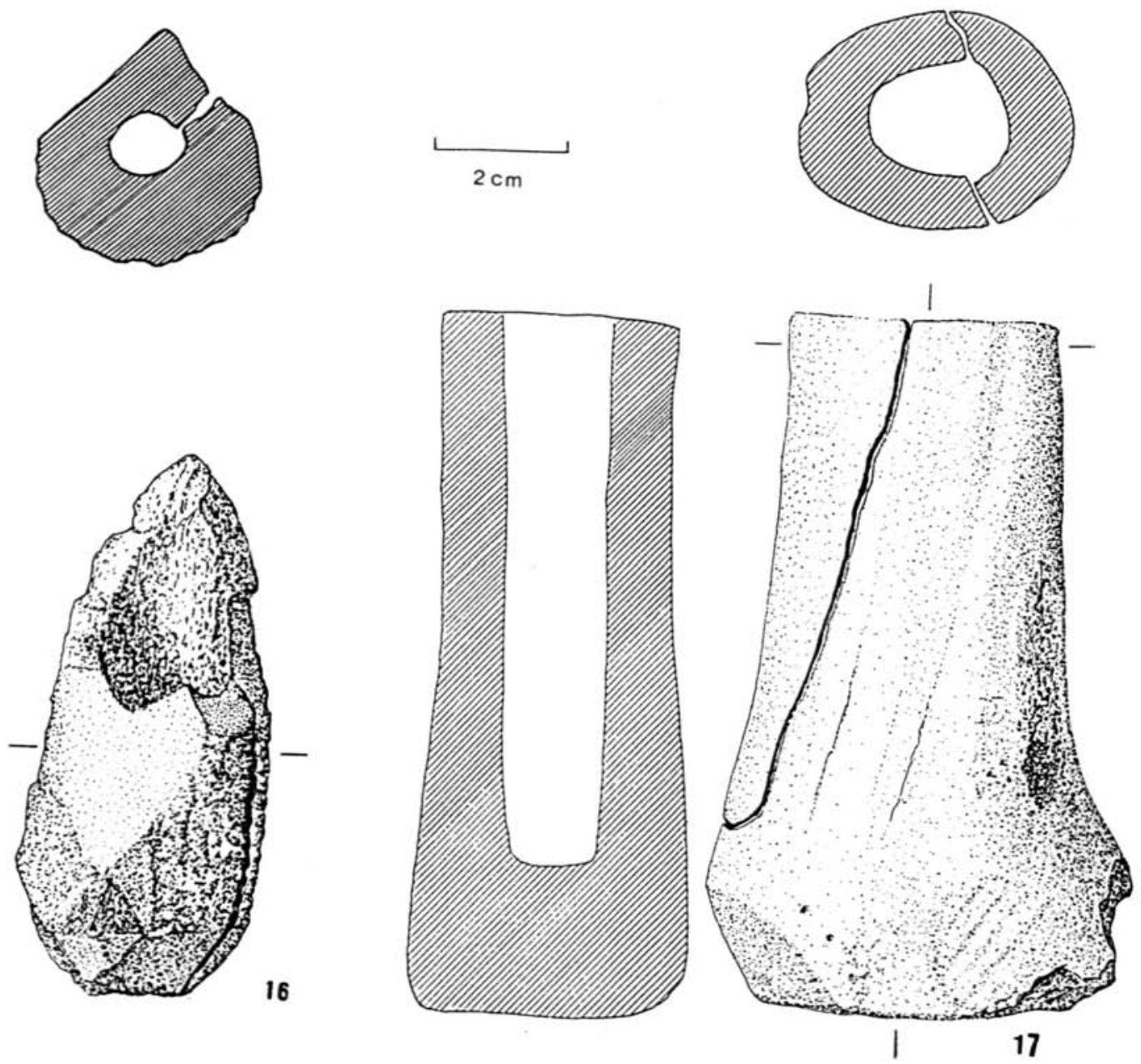
EstadJ: Completo, fractura del borde derecho del fuste.

Origen: A.

Medidas: $\mathrm{L}=112, \mathrm{~A}=(48), \mathrm{E}=36, \varnothing$ ext. $=(43), \varnothing$ int. $=23$.

Tipo: A.1.

Descripción: La extremidad distal está cortada horizontalmente, y el fuste está descortezado completamente, incluso en el borde derecho aparece el tejido medular. En el extremo proximal el borde izquierdo está cortado oblicuamente y el borde derecho presenta fracturas y cortes para eliminar el arranque de la luchadera basal. El vaciado interior afecta a toda la superficie medular, siendo su sección anular ovalada.

Observación: Es la única pieza en la que se ha encontrado el fragmento complementario al mango roto (en la misma zanja, pero en cuadros diferentes).

Núm. 18 (Fig. X)

Unidad: Conjunto Ofrenda.

Estado: Incompleto.

Origen: A.

Medidas: $\mathrm{L}=138, \mathrm{~A}=(43), \mathrm{E}=(45), \varnothing$ ext. $=(45), \varnothing$ int. $=19$.

Tipo: A.1.

Descripción: La extremidad distal tiene el borde algo rebajado. El fuste destaca por presentar una superficie muy lisa, incluso pulida y falta todo el borde derecho de la extremidad proximal (fracturación antigua). El vaciado interior presenta una sección anular rectangular. Tres fracturas longitudinales han deformado el mango.

Núm. 19 (Fig. XI)

Unidad: Material General.

Estado: Incompleto.

Origen: A.

Medidas: $\mathrm{L}=115, \mathrm{~A}=31,6, \mathrm{E}=24, \varnothing$ ext. $=32, \varnothing$ int. $=21$.

Tipo: A.1.1.

Descripción: A pesar de presentar la extremidad distal fragmentada, el borde derecho parece ser el original de la pieza (cortado horizontalmente). El mango tiene la superficie descortezada, pudiendose ver el trazado del tallado tanto en el fuste como en el extremo proxi$\mathrm{mal}$, en el que queda incluido el arranque de la primera luchadera. El vaciado interior llega hasta la zona más compacta del mango y tiene una sección anular ovalada. 

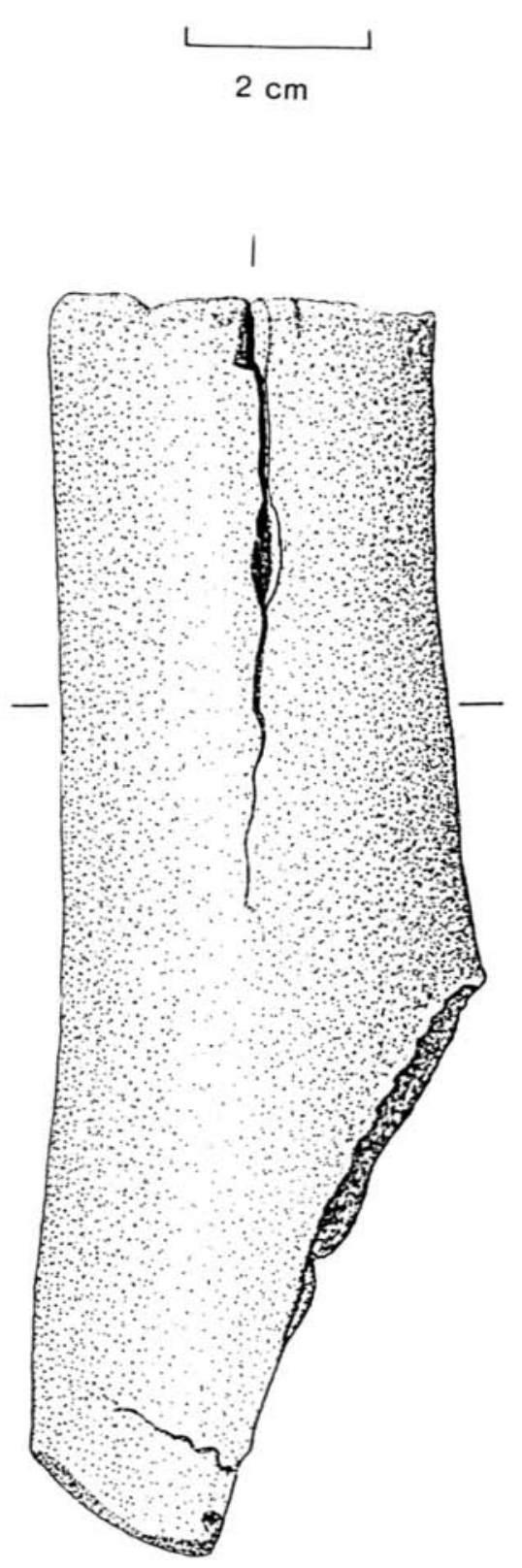
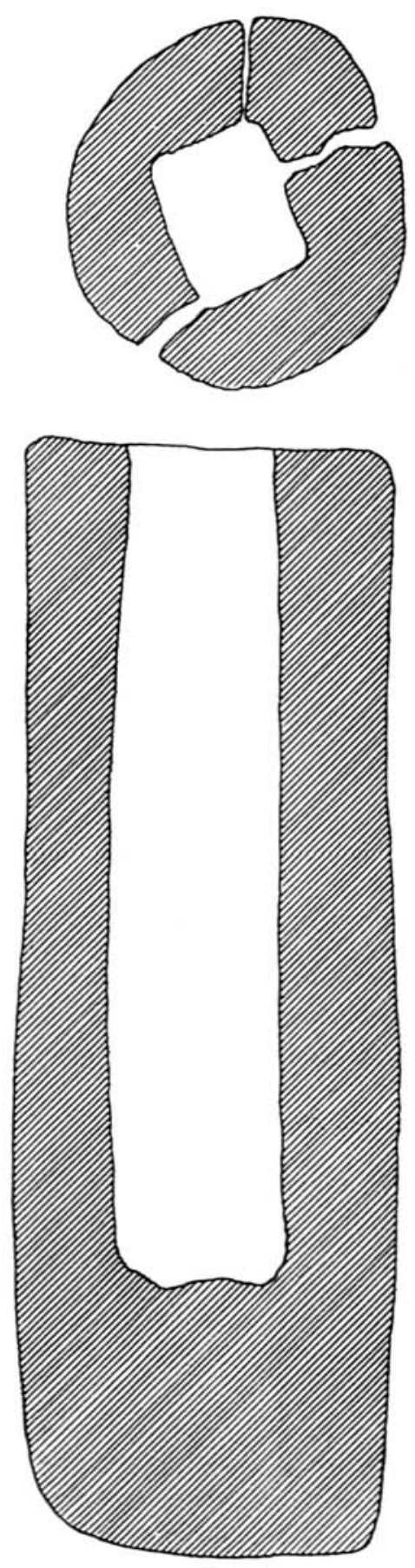
Núm. 20 (Fig. XI)

Unidad: Material General.

Estado: Incompleto.

Origen: A.

Medidas: $\mathrm{L}=144, \mathrm{~A}=49, \mathrm{E}=(31), \varnothing$ ext. $=$ ?, $\varnothing$ int. $=$ ?

Tipo: A.1.1.

Descripción: Parece haberse conservado la longitud original de la pieza, siendo imposible tomar otras medidas, ya que toda la mitad inferior ha desaparecido, a excepción de parte del arranque de la luchadera. En este caso, el borde derecho no ha sido recortado como en el mango n. ${ }^{\circ} 11$, sino que conserva su recorrido original. En el extremo proximal la luchadera ha sido cortada en su parte inferior, formándose un escalonamiento con respecto al arranque del asta, también rabajado. Las dimensiones del vaciado no se pueden precisar con más detalle, ya que gran parte del tejido medular, a excepción de la zona calcificada compacta a la altura de la rueda, ha desaparecido.

Núm. 21 (Fig. XII)

Unidad: Habitación/Calle.

Estado: Completo.

Origen: B.

Medidas: $\mathrm{L}=49, \mathrm{~A}=(41), \mathrm{E}=(38), \varnothing$ ext. $=(43), \varnothing$ int. $=(19)$.

Tipo: B.1.

Descripción: Tanto la extremidad distal, como la proximal parecen haberse extraído por aserrado horizontal, pero en la extremidad proximal los bordes han sido algo rebajados por algunos cortes de forma oblicua. La superficie del fuste es lisa y presenta algunas ranuras de poca profundidad. En la cara superior, cerca del extremo distal hay un corte horizontal no muy profundo. Se ha retirado la totalidad de la estructura medular, presentando la sección una forma anular ovalada.

Núm. 22 (Fig. XII)

Unidad: Basurero 2.

Estado: Completo.

Origen: $\mathrm{B} / \mathrm{C}$.

Medidas: $\mathrm{L}=68, \mathrm{~A}=38, \mathrm{E}=35, \varnothing$ ext. $=(39), \varnothing$ int. $=(12)$.

Tipo: B/C.1. 

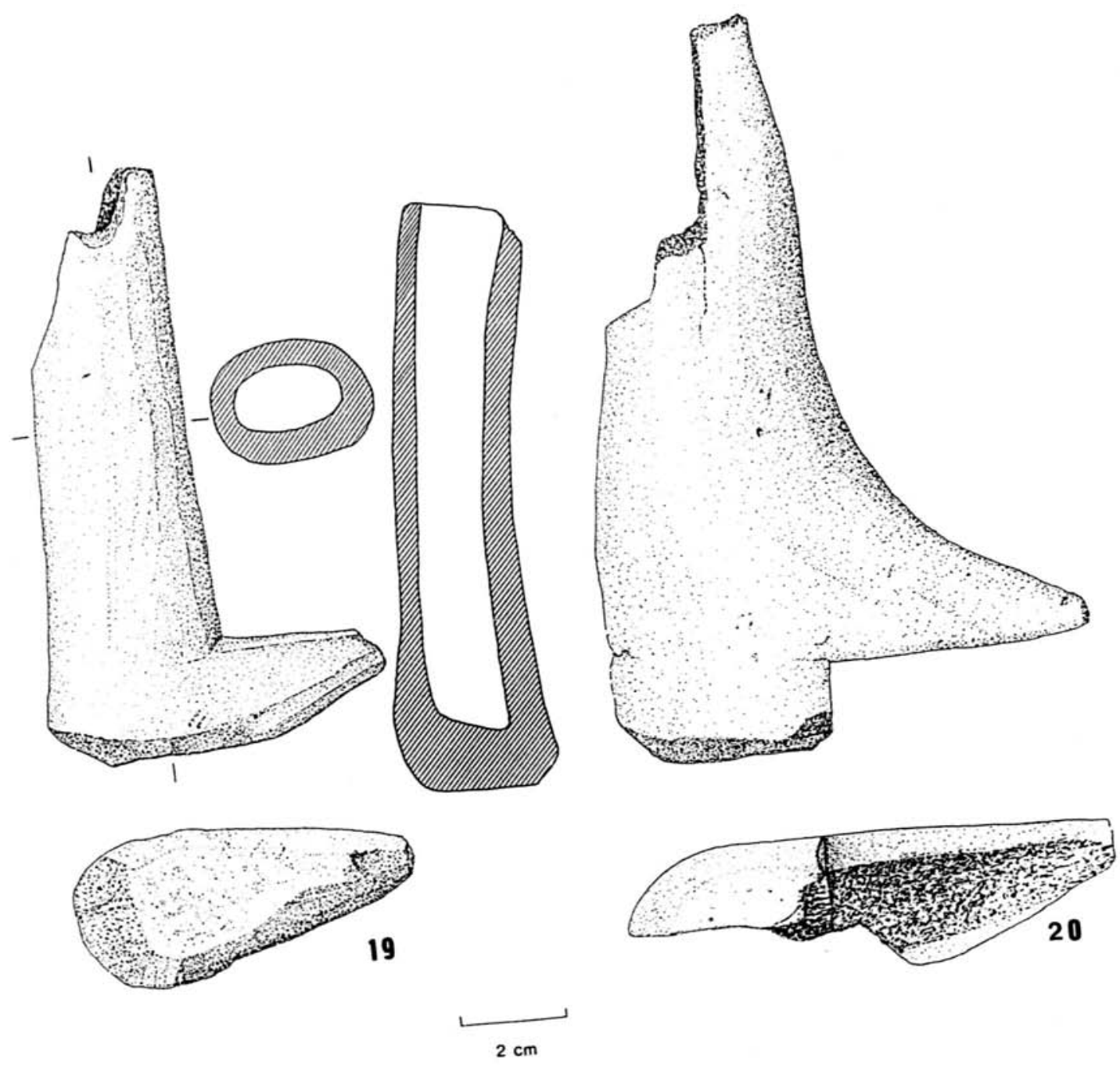

208 
Descripción: La extremidad distal presenta 5 facetas, producidas por cortes oblicuos vigorosos, mientras que la extremidad proximal ha sido extraida por múltiples cortes horizontales y de modo irregular. El fuste en el borde derecho está en parte tallado y la superficie en general es lisa, pero está mal conservada. En la cara superior tenemos un corte horizontal bastante profundo (¿posible funcionalidad de ayuda a una mejor sujeción del vástago?). El vaciado es bastante irregular, lo que puede ofrecer alguna duda al clasificarlo como mango.

Núm. 23 (Fig. XII)

Unidad: Materia General.

Estado: Completo, pero fracturado y deformado.

Origen: $\mathrm{B} / \mathrm{C}$.

Medidas: $\mathrm{L}=27, \mathrm{~A}=(47) \mathrm{L}, \mathrm{E}=(46), \varnothing$ ext. $=(47), \varnothing$ int. $=(29)$.

Tipo: B/C.1.

Descripción: El extremo distal presenta una superficie irregular y el extremo proximal ha sufrido diversos cortes horizontales para su extracción. El fuste, algo corto en comparación con los otros mangos, ha sido tallado a modo de facetas en toda la superficie, a excepción de una franja representada en el dibujo. La pieza ha sido vaciada totalmente y presenta una fractura que ha permitido al objeto aumentar su diámetro.

Núm. 24 (Fig. XII)

Unidad: Material General.

Estado: Completo.

Origen: $\mathrm{B} / \mathrm{C}$.

Medidas: $\mathrm{L}=45, \mathrm{~A}=(34), \mathrm{EL}=(34)$.

Tipo: No clasịficado como útil.

Descripción: No nos atrevemos a ver una funcionalidad de la pieza (siendo seguramente un producto de desecho por mala fabricación, fracturación o un objeto amortizado) aunque llama la atención, por presentar toda su superficie tallada. Tanto la extremidad proximal como la distal están descortezadas y facetadas, trabajo que parece haberse realizado con posterioridad a la extracción. También el fuste en su cara superior presenta un facetado en diferentes alturas e inclinaciones. El vaciado parcial no es intencionado, sino producido por la erosión o factores externos. 

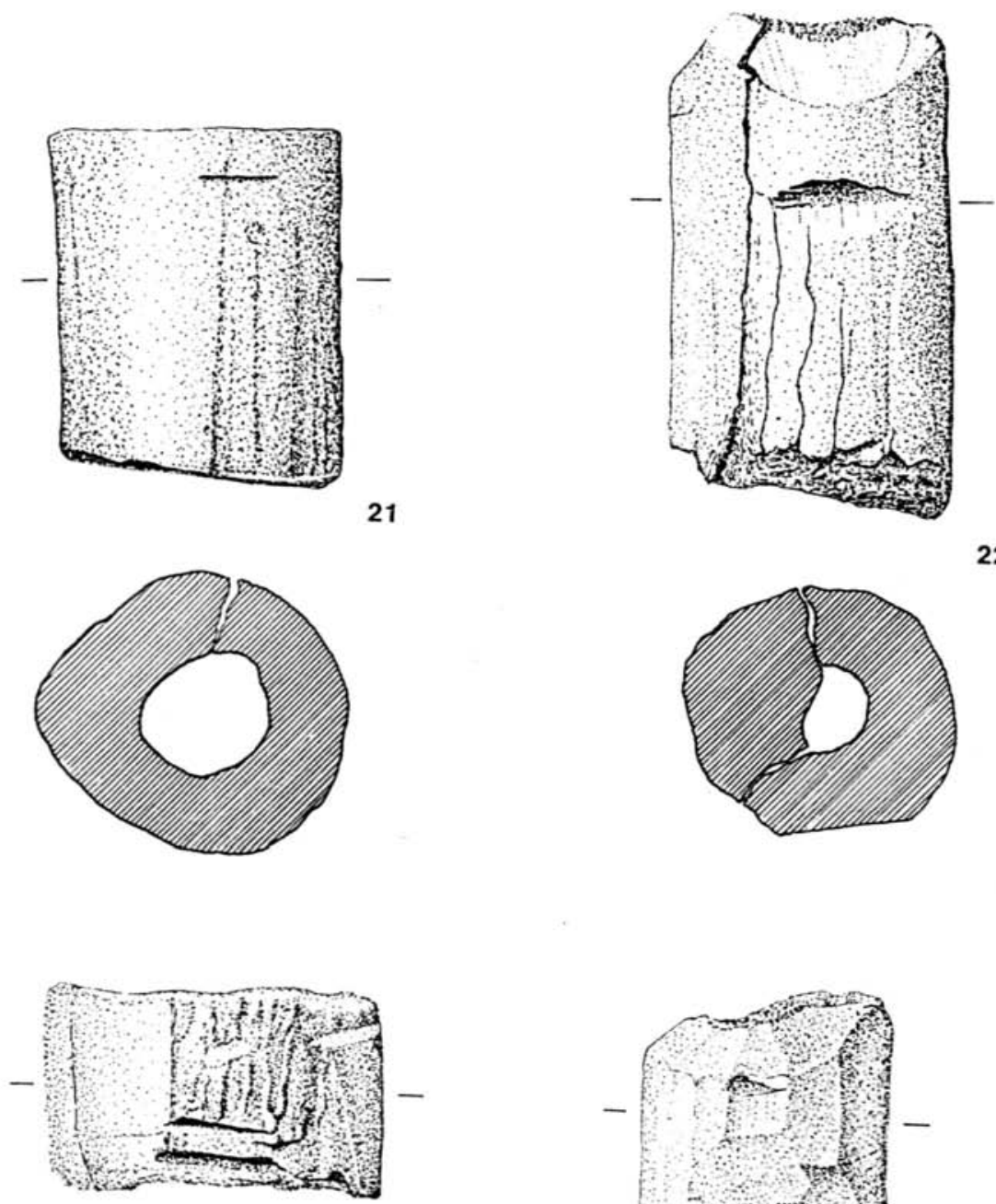

23
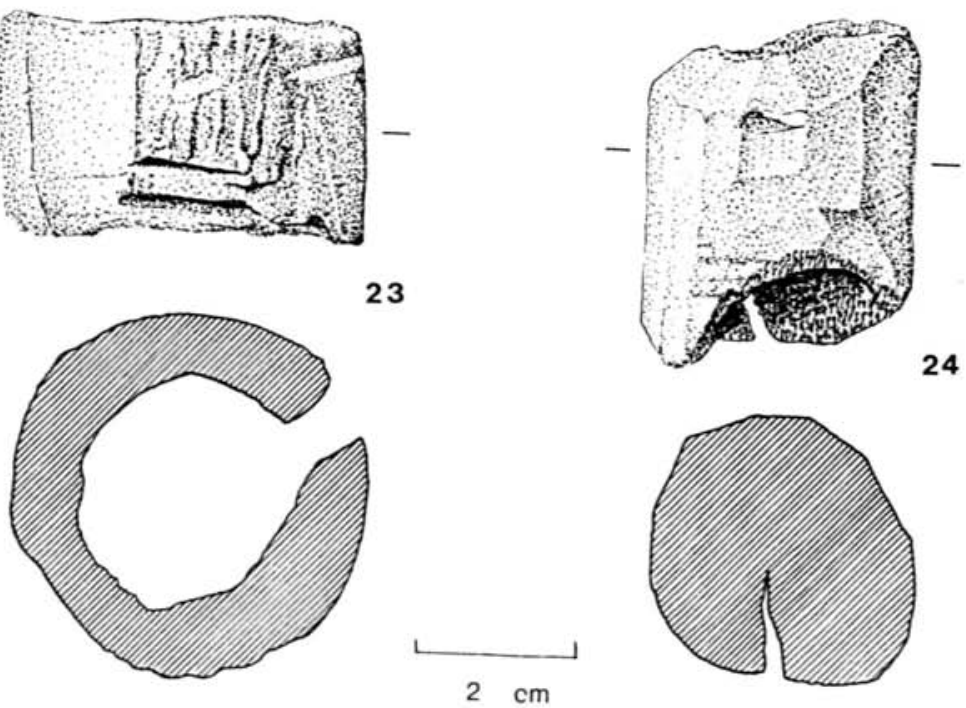
Núm. 25 (Fig. XIII)

Unidad: Basurero 4.

Estado: Completo.

Origen: F.

Medidas: $\mathrm{L}=51, \mathrm{~A}=27, \mathrm{E}=25, \varnothing$ ext. $=29, \varnothing$. int. $=7$.

Tipo: F.1.

Descripción: La extremidad distal está cortada por aserrado horizontal, manteniendo el fuste la estructura original de la luchadera. La extremidad proximal también está cortada horizontalmente, pero presenta sus bordes algo rebajados. No se puede afirmar con toda seguridad, que el vaciado intencional afecte a todo el mango, pero sí anotar la huella de forma cuadrada dejada por el vástago enmangado en la extremidad distal.

Núm. 26 (Fig. XIII)

Unidad: Habitación/Calle.

Estado: Incompleto.

Origen: E.

Medidas: $\mathrm{L}=(112), \mathrm{A}=(21), \mathrm{E}=(29), \varnothing$ ext. $=(14), \varnothing$ int. $=4$.

Tipo: E.1.

Descripción: Mango, en el que se ha cortado la punta de la cornamenta, para realizar un vaciado circular con un $\varnothing$ de $4 \mathrm{~mm}$. por unos $20 \mathrm{~mm}$. de profundidad. El fuste no ha sido trabajado a excepción de un facetado que presenta en el borde superior derecho. La pieza está fragmentada y en parte quemada.

Núm. 27 (Fig. XIII)

Unidad: Materia general.

Estado: Completo, pero fracturado longitudinalmente.

Origen: E.

Medidas: $\mathrm{L}=(112), \mathrm{A}=(21), \mathrm{E}=(20), \varnothing$ ext. $=(22), \varnothing$ int. (20).

Tipo: E.1.

Descripción: Pieza cortada horizontalmente, pero con los bordes de ambos extremos algo rebajados, el fuste completamente liso, pulido o incluso lustrado por presentar una superficie brillante. La pieza ha sufrido varias fracturas que la han deformado. Tampoco se puede asegurar el vaciado a lo largo de todo el mango, tanto por fracturas como por concreciones en su interior. 

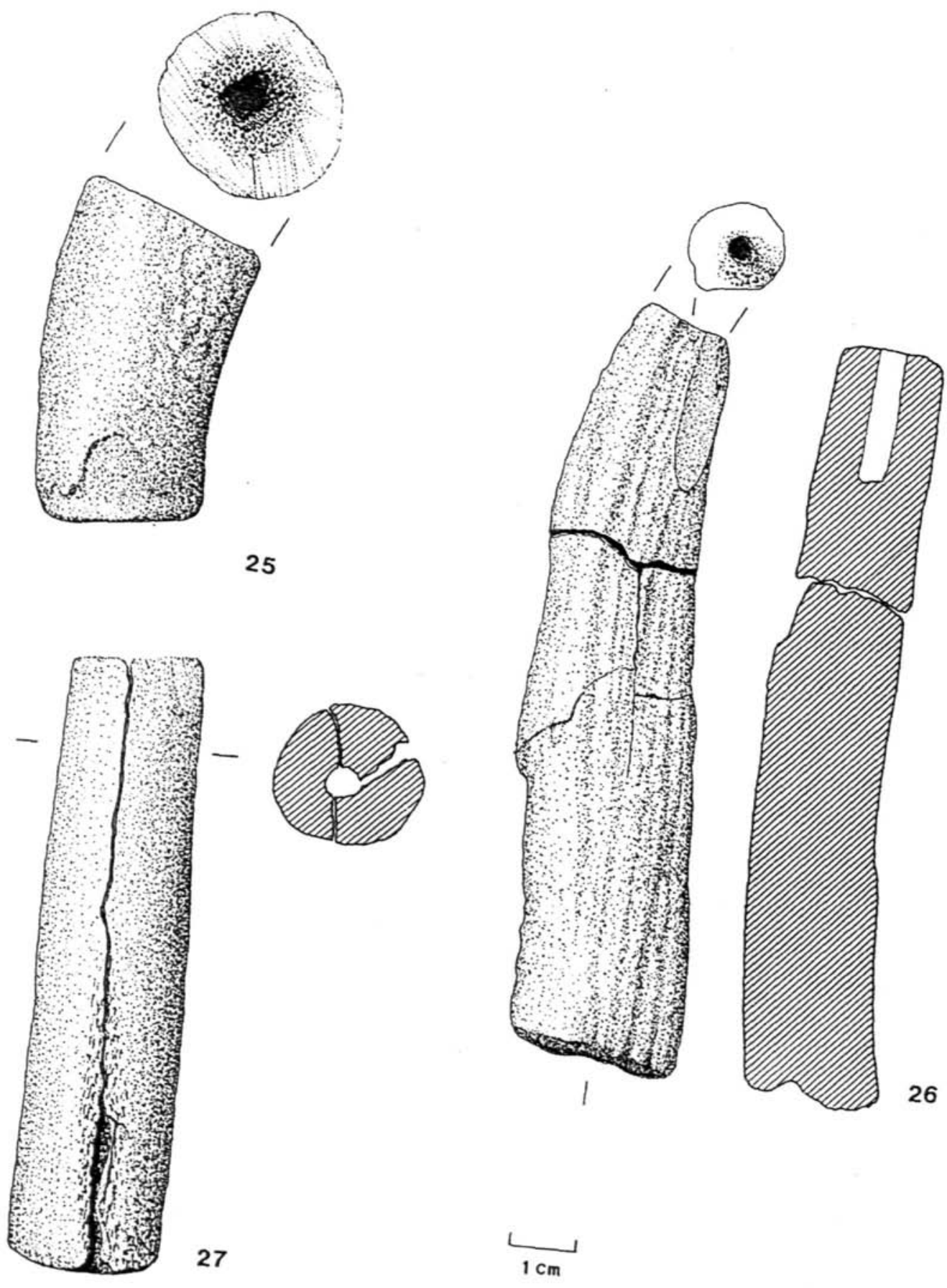


\section{BIBLIOGRAFIA}

ABÁsolo, J. A., RUIZ, I. PÉREZ, F. (1983): “Castrojeriz I. El vertedero de la Colegiata», Noticiario Arqueológico Hispano, n. ${ }^{\circ}$ 17. Madrid, 193-318.

Baldeón, A., Vegas, J. L., Llanos, A., SÁenz de IrRuti, F., Loza, R. y García, E. (1983): Museo de Arqueología de Alava, Vitoria.

BERDICHEWSKY SCHER, B. (1964): Los enterramientos en cuevas artificiales del Bronce I bispánico, Bibliotheca Praehistorica Hispana, vol. VI, Madrid.

BillambOZ, A. (1979): «Les vestiges en bois de cervides dans gisements de l'èpoque Holocéne essai d'identification de la ramure et de ses diféntes composantes pour l'étape technologique et l'interpretation palethnographique». L'Industrie de l'os Néolitique et de l'âge des Métaux, 1, Paris, 93-129.

CAMPS-FABRER, H. (1979): «Principes d'une classification de l'industrie osseuse neolithique et de l'age des métaux dans le Midi méditerranén". L'Industrie de l'os Néolitique et de l'âge del Métaux, 1. París, 17-26.

CAMPS-FABRER, H. y STORDEUR, D. (1979): «Orientation et definition del diferéntes parties d'un objet en os". L'Industrie de l'os Néolitique et de l'âge des Métaux, 1, París, 9-11.

Dauwors, M. (1977): «Stigmates d'usure présentés par des outils de silex ayant travellé l'os. Premiers résultats". Deuxiéme Colloque Internacional sur l'Industrie de l'os dans la Prebistoire, Abbaye de Sénanque 1976, 275-293.

EsCUDERO, Z. (1988): “El Soto de Medinilla», Revista de Arqueología, año IX, n. ${ }^{\circ} 89$.

HOFFMANN, VON H. (1959): «Zur Verzweigung des Hirschgeweihs”. Zeitschrift für Jagdwissenschaft, Hamburg Verlag, n. ${ }^{\circ} 1,1-23$.

LEISNER, G. (1943): Die Megalithgräber der Iberischen Halbinsel I. Der Süden, Berlin.

LIESAU, C. (1989): Análisis faunístico y estudio del material trabajado en asta de El Soto de Medinilla (Valladolid). Tesis de licenciatura inédita.

Llanos, A. (1976): La Hoya: un poblado del I Milenio antes de Cristo, Diputación Foral de Alava.

Llanos, A. (1983): Museo de Arqueología de Alava, en BALDEON et alii, p. 121.

MANRIQUe MAYOR, M. A. (1980): Instrumentos de bierro de Numancia, Ministerio de Cultura.

MURRAY, C. (1979): «Les techiniques de débitage de métapodes de petit rumiants a Avernier-Port». L'Industrie de l'os Néolitique et de l'âge del Métaux, 1, París, 27-35.

Ruiz Nieto, E., MartíneZ Padilla, L., TORRalba Reina, F. (1983): «Ensayo metodológico para el estudio de materiales óseos". Antropología y Paleocologia bumanas, n. ${ }^{\circ} 3$, Granada, 129-145.

RODANÉs VICENTE, J. M. (1987): La industria ósea prebistórica en el valle del Ebro. Neolítico-Edad del Bronce, Zaragoza.

RUST, A. (1937): Das altsteinzeitliche Rentierjägerlager Meiendorf, Neumünster.

RUST, A. (1943): Die Altstein und Mittelsteinzeitlichen Funde von Stellmoor, Neumünster.

SaCristán de LAma, J. D. (1986): La Edad del Hierro en el Valle Medio del Duero. Rauda (Roa, Burgos), Valladolid.

SEMENOV, S. A. (1981): Tecnologia prebistórica, Ed. Akal, Madrid.

Vicente Redón, J., Punter Gómez, P., Escriche Jaime, C. y Herce San Miguel, A. I. (1986): La ciudad celtibérica de la Caridad. Caminreal (Teruel), Seminario de Arqueología y Estudios Turolenses, Colegio Universitario de Teruel.

WATTENGERG, F. (1959): "La región Vaccea. Celtiberismo y romanización en la Cuenca Media del Duero», Bibliotheca Praehistorica Hispana, vol. II, Madrid. 